\title{
Gilberto Friedman
}

\section{Time to die!}

Received: 15 January 2014

Accepted: 1 February 2014

Published online: 27 February 2014

(C) Springer-Verlag Berlin Heidelberg and ESICM 2014

G. Friedman (凶)

Universidade Federal do Rio Grande do Sul,

Porto Alegre, RS, Brazil

e-mail: gfriedman@hcpa.ufrgs.br

"Dying belongs to life, like being born.... Someday we'll know that death can't steal anything that our soul has conquered because its achievements are identified with life itself." Tagore, an Indian poet, incorporates death as part of life and not as an unwelcome intruder:

Who can determine the best time to die?

Who can choose the right time to let someone die?

Who can or should help you choose the best time for someone to die?

I will tell an episode that marked my professional life.

Part I: A married elderly patient was admitted to ICU bed number two in respiratory failure and shock. The medical team promptly started an aggressive resuscitation to support life.

Part II: In the following days, an underlying metastatic cancer was found.

"What should we do?" asked some young doctors. I, the experienced physician, explained to them that we must wait 2 or 3 days to understand how her condition was evolving and then decide what to do. Basically, as I get more experienced, I wonder more and more about what really we should do at this time!
Part III: The patient did not improve. It seemed clear to everyone, young doctors, and me that death was unavoidable and that any further treatment was futile. The team decided to talk to her husband to propose an end-oflife procedure.

Part IV: I returned to work the next afternoon. The medical team was gathered, anxious, and somewhat indignant after discussing with the patient's husband. The doctors, mostly young, were especially angry because he seemed not to accept the proposed end-of-life care plan. After all, what was happening? They asked me to talk with her husband to convince him of the plan that seemed most worthy to her. I talked with her husband for a few minutes. As a result of the short conversation, the young doctors must have thought that everything was resolved and that her husband had finally understood that his beloved was dying.

To the surprise of all, I ordered that everything should be kept for a week and the status quo should be maintained! "What? How come?" some young doctors claimed. I told everyone that her husband explained to me that in a week the couple would celebrate their 50 years of marriage and he wanted to commemorate it with the love of his life. This was her last wish.

Part V: A week after, her husband sat beside his wife, took her hand lingeringly, and probably whispered lovely words. After long minutes, he removed the wedding ring from his wife's finger, walked in our direction, thanked us, and asked that all life support could be withdrawn.

Many people regret during or after these moments that they did not have time to say what they felt to the other. In contrast, this gentleman was quiet all the time, and seemed to regret nothing, absolutely nothing!

"Only in the agony of parting do we look into the depths of love."

George Eliot 
Part VI: I do not remember a situation of end-of-life where I have been so sure of my decision. I do not regret one second my choice. Critical care physicians should prepare or prepare the family for this moment. However, in this case the husband was clearly more prepared than the doctors who appeared to understand nothing.

I was afraid that some young doctors might have confronted me! It is acceptable to extend the life (death?) of a patient for a week to satisfy a wish of this kind? I would have argued yes, of course! However, no one questioned the decision. It seems that at the end everyone understood that a dignified passage with fraternal care and with less suffering was guaranteed.

Is this not our mission?

Conflicts of interest There is no conflict of interest. 